\title{
On the Importance of the Plumber: The Intersection of Theory and Practice in Policymaking for Federal Financial Institutions
}

Douglas J. Elliott

\begin{abstract}
The federal government's role as lender and insurer is very important, with over $\$ 1.4$ trillion of loans and guarantees and at least $\$ 7$ trillion of insured risk. Tens of millions of Americans benefit from housing loans, student loans, flood insurance, etc. Yet the federal financial institutions established to run these activities are often created almost as an afterthought, with little focus on their structure. This paper emphasizes the crucial importance of ending this neglect and recognizing how proper structure can help avoid major failures, such as the current problems at the Pension Benefit Guaranty Corporation, and enhance successes. The author also challenges the economics profession to provide more guidance on a range of specific analytical issues with real-world implications, because economists have often failed to extend analyses derived from the private sector into useful formulations for public sector practitioners.
\end{abstract}

Federal Reserve Bank of St. Louis Review, July/August 2006, 88(4), pp. 259-71.

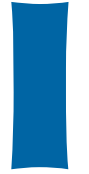

'd like to start by thanking the Federal Reserve Bank of St. Louis for sponsoring this conference on a very important topic that is dear to my heart, but is often neglected by others. I was thrilled to hear about the conference even before our hosts did me the honor of inviting me to speak.

My talk today will be very different from the brilliant economic analyses that you will likely hear from the other speakers. It will be full of personal opinions and observations rather than mathematical logic or statistical analyses that can be proven or disproven. In some ways it is a letter from the front-lines where public policy, politics, and bureaucracy clash. In consequence, you deserve some explanation of who I am and from where my opinions derive.

\section{BACKGROUND}

I was an investment banker for nearly two decades, principally with J.P. Morgan, and my clients were insurers, banks, and other financial institutions. My job responsibilities and my analytical nature thoroughly taught me how to take apart and analyze a financial institution. When I reached a point in my life where I wanted to actively contribute to public policy, it was only natural that I focused on the federal government's own financial institutions. After extensive informational interviews with policymakers, it became clear that these important institutions do not receive nearly the attention that they deserve. In consequence, I gathered together a board of directors of like-minded policy experts and founded the Center On Federal Financial Institutions (COFFI). We are a nonpartisan, and nonprofit, think tank that focuses solely on federal lending and insurance activities. You can find out more at www.coffi.org.

We have carved out a role in educating policymakers, journalists, and the public about issues surrounding these critically important institutions.

Douglas J. Elliott is the president and founder of the Center On Federal Financial Institutions.

(C) 2006, The Federal Reserve Bank of St. Louis. Articles may be reprinted, reproduced, published, distributed, displayed, and transmitted in their entirety if copyright notice, author name(s), and full citation are included. Abstracts, synopses, and other derivative works may be made only with prior written permission of the Federal Reserve Bank of St. Louis. 
We largely avoid advocacy of policy positions because we believe this would risk alienating some policymakers who would otherwise benefit from a greater understanding of how these institutions actually work. We are still at the phase of explaining that if you push this button, certain things will happen, and if you pull that lever, other things will happen. I will be a bit more opinionated than that today, secure in the knowledge that this audience does not need basic points elucidated and hopeful that you will accept our political neutrality. You can do so in some confidence.

For example, the New York Times referred to our material as being "without a hint of dogma or advocacy" as well as "refreshingly understandable." Naturally, the opinions I express today are my own and not those of COFFI.

I apologize if I seem to be more of a "man with a mission" than the methodical, intellectual economists who are making the other presentations. I believe three things passionately:

- Federal financial institutions are extremely important in the lives of tens of millions of Americans. \$1.4 trillion of credit and over $\$ 7$ trillion of insurance make a big difference, for good and ill, especially given the focus of the programs on policy issues important to our country.

- These institutions do great good when run well and great harm when run badly.

- Our nation needs your help. Some of the most brilliant minds in this country are here as speakers, and everyone here is involved in setting the terms for public policy or in executing those policies. The rest of my talk will center on issues that I believe deserve your attention.

\section{THE IMPORTANCE OF THE PLUMBER}

To put my chosen focus in a broader context, I would like to propose a metaphor, borrowed from Bob Litan, one of my Board members and a fellow speaker here. I am here as a plumber, devoted to managing the massive liquidity that is at the disposal of the federal government and is directed toward so many policy goals. The other speakers are the scientists and visionary engineers who show us what can be done. I am grateful for their important work, but sometimes it seems that we collectively neglect the simpler things that actually keep the fluids going where we want them to go. Yet, we all know how bad things can get when the plumbing breaks and we know the feeling of helplessness when the water will not come out of the tap.

Economists and political scientists have written great analyses examining the circumstances under which the federal government might usefully be in the business of lending money or insuring risks. This research matters a great deal because it is an important factor in framing how policymakers think about proposed new federal financial institutions. It helps filter out bad ideas and encourages good ones, although it will always be true that political considerations are likely to play the predominant role in the final decisions. I applaud the previous research, and I would encourage more.

\section{LIKE DIAMONDS, FEDERAL FINANCIAL INSTITUTIONS ARE FOREVER}

However, my primary interest lies at a different level, beneath the existential questions of whether these institutions should be here. The federal government has a long history as a lender and insurer, and there is no sign that this is going to change. If anything, concerns about the federal budget deficit are likely to encourage an expansion of these programs. Lending and insurance programs allow politicians to throw out multibillion dollar figures for the volume of good their proposals will provide, without having the budget cost approach those levels. This is especially true if politicians use overly optimistic figures for the proportion of borrowers who will actually pay the loans back or the proportion of insureds who will submit claims. There are not a lot of other areas in the government where you can propose a program that directs $\$ 10$ billion to some sector and claim at the same time that it will directly make 
money for the government, at least not areas where the budget scoring might back you up.

Even if new programs are not introduced, it is a very rare occasion when an existing federal financial institution slides off into the sunset. Doubtless, this is sometimes because the underlying need remains, but in other cases it is probably more a function of the creation of constituencies who come to value an existing program. Politicians are very aware that it is much easier to withhold something in the first place than it is to take something back.

So it seems that the federal government is likely to remain a massive lender and insurer indefinitely. Given this, it behooves us to make sure that these financial institutions are run well. Notice my constant references to "financial institutions." I strongly believe that one of the underlying reasons for financial crises and chronic underperformance at some of these institutions is that their structures were established with insufficient regard for how they would function as a financial institution. There is a strong tendency in Washington to focus on the grander policy issues, such as ensuring access to a college education, and to assume that creating a financial institution will naturally follow in an optimal manner. Therefore, the pension insurance system was designed by pension experts, student lending by education experts, etc. Of course, the specific policy expertise is critical, but it needs to be leavened with an understanding of financial institutions. Otherwise bad things can, and do, happen.

Most of the key issues to be discussed fall into one of four categories: structure, budget rules, human resources, and management tools.

\section{STRUCTURE}

The failure to think about programs as financial institutions can be very harmful if it results in a flawed structure.

\section{Federal Communications Commission Spectrum Auction}

An extreme example of this is the Federal Communications Commission (FCC) spectrum auction that occurred in the midst of the late, lamented bubble. The federal government determined that parts of the radio spectrum could be turned over to the private sector and that the most effective way to do this was through an auction. This may have been an excellent general idea, but appended to it was an egregious flaw. Congress wished to ensure that smaller businesses and minorities not be locked out of the bidding because of difficulty in finding up-front funding. Again, in itself this may have been a very laudable goal. However, almost as an afterthought, it was determined that the FCC should agree to accept installment payments from small and minorityowned businesses that met certain criteria.

What this meant was that the FCC, with no previous experience as a lender, was now going to effectively lend certain bidders the money to buy the spectrum they desired. Thus, Congress set up a multibillion dollar lending operation from scratch and without much consideration of the optimal structure. The actual structure contained many risky features:

- The borrowers generally were betting the success of their companies on the use of their particular spectrum. Therefore, the program's role basically was to provide project finance, which is riskier than general lending.

- There was little lending expertise at the FCC.

- Borrowers were targeted based on their likely difficulty in attracting private finance.

- There was little requirement for equity to exist at the bidding firms, but installments were priced as if they were true loans. Every smart lender knows that calling something a "loan" is much less important in reducing risk than ensuring that someone else takes the first loss. Many a project has been pitched to lenders as "borrowing," when it is apparent that the risk is basically equity risk and should have been priced that way.

I should stress that it was not necessarily wrong to set up a program that took on certain of 
these risks, particularly lending to borrowers with market-access problems. It is the combination of these structural risks that compounded to dangerous levels.

The results were sadly predictable. The bubble burst after the auctions were completed but before most of the installment payments were made. This might not have mattered as much if the FCC's new unit had nailed down the ability to take back spectrums. There would have been an opportunity cost from reselling spectrum under less propitious market conditions, but this still would have provided substantial recoveries. Instead, companies that collapsed have been able to retain control of their spectrum in bankruptcy, leaving the federal government as one more unhappy creditor.

Proper thought given to this program as a financial institution would undoubtedly have raised questions that would have led to a superior structure. I know that the Office of Management and Budget raised objections to the approach that was ultimately followed, but various political and bureaucratic issues trumped their logic.

\section{Pension Benefit Guaranty Corporation}

Another example of a failure to focus on the nature of an entity as a financial institution is the Pension Benefit Guaranty Corporation (PBGC). This is a less clearcut example in some ways, since there was considerable discussion of certain insurance principles from the beginning, including the need to have some risk remain with employees and retirees in order to reduce moral-hazard issues. Yet, the outcome was still to design an insurer with structural risks, including the following:

- No ability to choose clients. All corporate pension funds with certain minimal characteristics were insured.

- Overall price levels were fixed on an ad hoc basis. I'm told that, back in 1974, the pension insurance premium was going to be set at 50 cents per participant per year, based on a study of historical losses that did not take into account likely changes in behavior once there was a federal insurer. In the end, it was bumped up to a dollar per participant because an important senator just thought that it was worth having a margin for error and that a round dollar sounded right. It is hard to imagine this kind of ad hoc decision, or the earlier mentioned structural problems, if the establishment of a federal financial institution were seen as more than an ancillary activity.

- Prices initially did not vary with risk levels and still have only a loose relationship to risk.

- No meaningful regulatory authority. Regulatory power often substitutes for the lack of an ability to choose whether to take a client and how much to charge. Mandating certain operational and financial standards can reduce risks to levels more appropriate to the premiums charged. Private sector banks do this by insisting on loan covenants that give them great leverage if a company deterioriates too far. The Employee Retirement Income Security Act does set down certain standards of behavior for pension funds, but the regulatory power is at the Department of Labor and the Internal Revenue Service, not the PBGC.

- Little authority to negotiate workouts with troubled insureds. Private lenders naturally prefer not to lend to firms that will become troubled, but they recognize that concessions are often necessary when a company does fall on hard times. More-lenient terms are combined with tough requirements to fix operating and financial problems. The PBGC's ability to effectively negotiate such a workout is very limited.

As with the FCC example, let me stress that structural issues must be looked at in combination. Sometimes a structural risk is justified by other policy objectives but becomes excessively dangerous in tandem with another risk.

\section{THE NEED FOR NEW "COMMANDMENTS"}

It would be a real step forward if we could persuade Congress to establish a statutory require- 
ment that any new federal financial institution must have a business plan that addresses a number of key structural issues. Admittedly, it would be difficult to enforce quality standards for these business plans, but bureaucrats and politicians do not like writing things down that will sound stupid later. Putting words on paper and having them reviewed can often help avoid the worst potential problems. By the way, I do not mean to suggest that the private sector is any better when dealing with seemingly peripheral issues where no one is reviewing the thinking. Having worked on Wall Street for almost 20 years, I have heard a lot of stupid ideas. It's just that private financial institutions and markets have many built-in checks that cause most ideas to be reviewed by people with a monetary stake in the outcome.

The Office of Management and Budget (OMB) generally opines already on the creation or significant revision of federal financial institutions. However, statutory authority would significantly increase their institutional ability to resist bad structures. Besides, the OMB is stretched thin and it would be better to eliminate many of the bad ideas before they reach that agency, to minimize the chance that some will slip through. I do not mean to neglect the role of the Congressional research arms, such as the Government Accountability Office, the Congressional Budget Office, and the Congressional Research Service. However, they also have serious resource and institutional constraints that limit their ability to completely filter out bad structural ideas.

Let me say again that I understand that politics, in a democratic system, always has the potential to overcome financial expertise-and sometimes even common sense. However, I also believe that a systematic discipline can avoid many errors. A happy example of this is the Federal Credit Reform Act of 1990, the budget rules that have guided federal lending activity for over a decade.

\section{Budget Rules}

Budget rules are a very powerful way of influencing behavior in any large organization, especially one with few binding external constraints. Prior to the implementation of the Act in 1992, federal credit programs faced the same budget rules as other federal programs. If a dollar of cash went out as a loan, it looked on the budget pretty much the same as if a grant were made with that dollar or part of a weapons system were bought. Similarly, receiving a dollar in repayment had the same effect as collecting a dollar in taxes or user fees. Needless to say, this simplistic approach created major distortions in government decisionmaking because lending is a multiyear activity that needs to be viewed that way. The practical problems often stemmed from the strong political incentives to minimize budget costs in the nearterm, particularly the first year, even if long-term costs were increased. Three distortions stand out:

- There was a significant disincentive to expand even worthy direct loan programs. The new outlays would hit the budget in the politically critical first year, whereas the offsetting repayments would be years in the future. It is interesting to remember that President Johnson first sold part of Fannie Mae to the private sector partly to take the growing program off-budget. Whether that was a good or a bad decision, it was too important to be decided as a result of bad budget rules.

- Incentives existed to destroy economic value by taking certain actions that raised a great deal of cash up-front. For instance, packaging government loans together and selling them to the private sector at a distinct economic loss would still reduce the near-term budget deficit by bringing in cash. This is not to say that loan sales were necessarily uneconomical, but rather to point out a structural bias.

- Cash budgeting heavily tilted the playing field in favor of loan guarantees, even when direct loans made more programmatic sense. Loan guarantees were essentially costless in their first year, since defaults rarely occur that quickly. They could even show an initial profit if there were an upfront guarantee fee that more than covered administrative expenses. 
A related structural problem stemmed from the use of "revolving funds" as the basis for many loan programs. Congress would start a program with an appropriation to its revolving fund, which would be used to fund loans. Loan repayments and interest went back into the revolving fund and could be lent out again, without further Congressional action. Many advocates of credit reform felt that this excessively limited Congressional scrutiny and control of loan programs.

The Federal Credit Reform Act completely changed the rules, in an attempt to level the playing field between loans, guarantees, credit insurance, and grants. A projection is made of future cash flows for each year of new credit authority. These cash flows are then discounted back at the zero coupon government borrowing rate for bonds maturing in the same year as the cash flow. The net present value shows up as a subsidy expense on the budget, assuming the value of outflows exceeds that of inflows. If the inflows are worth more, then a negative subsidy is shown, equivalent to revenue dollars from other sources. It is worth noting that administrative expenses are not included in the subsidy calculations but continue to be budgeted on an annual cash basis. Congress has been reluctant to give up specific control over administrative costs.

There is a strong consensus among budget experts that the Federal Credit Reform Act has improved decisionmaking, as would be expected. There is always room for gamesmanship in any budgeting process, as well as room for ignorance and misunderstanding, but this law clearly acts as a restraint on bad decisions and as a subtle encouragement for good ones.

Nonetheless, this is an area to which I would like to devote a considerable part of my time here today because there are a number of practical questions for which we could use the help of top economic thinkers. Some of these questions may seem to have obvious answers, but that is precisely my larger point. There is often a great lag between advances in economic thinking and when these concepts become part of the policymaking process. Indeed, it may sometimes seem as if there is a disconnect rather than simply a time lag. We need help making the case for sound economics and well-considered thinking on how answers that were formulated primarily for private financial institutions may need to be modified for the public sector. This latter point is important because many in Washington assume that answers developed for private sector institutions are not likely to be valid in the public sector. They are sometimes right in that concern, and so our analysis needs to consider that factor.

\section{Discount Rates and Floating-Rate Loans}

Let me start with what seems like an easy question. What discount rate should we use for a floating-rate loan made by the government? The Federal Credit Reform Act indicates that the "effective maturity" should be used in determining the appropriate discount rate. This has generally been interpreted, in the traditional sense of maturity, as being the point in time when the money is repaid. The student loan programs are the main federal credit programs that use floatingrate loans, and the final maturity on these loans tends to be about 10 years, although it varies considerably. The lending rate is based on a 91-day Treasury-bill rate but is reset only once per year, not every quarter. Currently, this is scored for budget purposes in the same way-as if there were a series of payments based on a fixed rate. That is, the principal and interest payments expected in year one are discounted with a 1-year T-bill rate, the second year's payments with a 2-year rate, etc. (We will return later to the question of whether the government's cost of funds should be used, as it is now, or whether a risk-adjusted rate would be more appropriate.)

This has raised the analytical question as to whether it would be more appropriate to use a discount rate based on short-term interest rates rather than using a rate based on the final maturity of the loan. There was little or no discussion in Congress of this issue when the Federal Credit Reform Act of 1990 was passed, in part because there were no significant floating-rate lending programs at that point. (Student loans were still offered on a fixed-rate basis at that time.) There has been discussion of this issue periodically since then, including in the early days of the Direct Lending program, but no changes have been made. 
Let me lay out the case for changing the approach. As noted above, Congress has chosen to use the government's cost of funds as the basis for the discount rates. Congress further chose to define the cost of funds not as the actual borrowing rate experienced by the Treasury Department for a particular program, but as the borrowing rate that eliminated any interest rate risk on a fixedrate loan. That is, the rate on a 10-year government borrowing is used as the discount rate for a payment 10 years in the future, even if the likelihood is that the Treasury Department would finance the 10 years through a series of shorterterm borrowings that were rolled over. Regulators, financial markets, and financial economists agree that this is the least-risky way to finance a future payment.

Similar logic would suggest that the leastrisky way to finance a floating-rate lending program would be to borrow at a floating rate with similar characteristics. That is, funding the student loan program through 91-day T-bills would produce future interest costs that would most closely match the expected interest receipts. (The most precise match would have to take account of the fact that the rate is a 91-day rate but is only reset once per year. The best fit might therefore be an instrument a bit longer than the 91-day T-bill, although not as long as the 1-year T-bill.)

This funding pattern might not intuitively seem to be the least-risky choice, since the cost of funds would be considerably more variable than locking in a 10-year fixed rate. However, this looks at only one-half of the equation. Congress presumably cares about the net cost of the program, which is determined by the difference between the lending rate and the cost of funds. This difference is highly volatile today because the 10-year bond rate can move significantly differently from the 91-day T-bill rate. Using the same rate for both would eliminate this source of volatility.

Congress appears to make decisions as if the discount rate were the actual underlying cost of funds. On that basis, evaluating the floating-rate student loan program by using a 10 -year fixed rate is equivalent to a private lender borrowing long term and lending short term. Lenders sometimes do this for pieces of their overall portfolio as an explicit interest rate bet, but it is considered irresponsible if applied as a consistent strategy to the whole firm.

For a private lender, this mismatch would produce major swings in profitability. For the government, the mismatch between the basis for determining the discount rate and the interest rate paid by students has produced similar oscillations in the budget cost of student lending. These swings could be dampened sharply by eliminating the artificial mismatch in the federal budget.

A friend of mine who is a respected financial economist believes strongly that a floating rate would be more appropriate economically, but is frustrated in proving this to policymakers because there is so little written on the subject. The problem seems too simple for a research journal, given that this question is a settled one for private sector firms, even though it is important and not settled in the real policy world. We could use your help in showing that the private sector analysis applies here, or that it needs to be modified, or even that the current budgeting approach is actually right for reasons unique to government budgeting.

The issue of using a floating discount rate has important real-world implications. Switching to its use would likely trigger two policy changes, assuming normal yield curves prevail. First, it would tend to be more favorable to direct lending by the federal government, in comparison with guaranteed lending by the private sector, than is true under today's rules. The direct loan program experiences upfront cash outflows when the government makes a loan, which are offset by receipts spread over many years. In contrast, the guaranteed loan program has payments and receipts that are more mixed over time. This timing differential makes the direct loan program much more sensitive to discount rates than is the guaranteed loan program. This provides two disincentives for direct lending: (i) The average long-term discount rate is likely higher than a floating rate would be and (ii) current rules create the mismatch that I described, resulting in budget volatility. Congress does not like volatility of budget costs any more than private sector firms like volatile profits. The other major effect would be to lower the average budget cost of student 
loans, again assuming a normal yield curve. This would likely result in the authorization of higher volumes of lending.

\section{Discount Rates and Risk Adjustments}

The second question that I will highlight may also seem simple, depending on your viewpoint, but has even greater implications for federal lending. Should the federal government use a discount rate that reflects the uncertainty of future cash flows from a lending program? Congress made the decision in 1990 to base the discount rate on the federal government's cost of funds rather than on a risk-adjusted basis. Unlike the floating-rate question, there was a great deal of discussion on this point, to which I may not do full justice, as I was not involved in the debate.

The arguments for a risk-adjusted rate were largely modeled on the arguments that have prevailed in economic analysis of private sector financial institutions. Essentially, debt and equity investors are risk-averse and therefore require a higher return from activities that have uncertain future cash flows. This is captured with discount rates by using a higher discount rate for riskier expected cash flows. A variation of this argument that focuses on the allocation of public resources suggests that if the interest rate for all borrowers is held constant in a lending program, more value is being provided to a high-risk borrower than to a low-risk borrower, if for no other reason than that their private sector alternative borrowing rate would be higher. This is useful to know for two reasons. First, it is desirable to keep track of where we are allocating valuable resources. Second, the value to the recipient means that there is an opportunity cost to the government in failing to charge the full amount that the borrower would be willing to pay and this opportunity cost varies with the riskiness of the borrower.

The theoretical arguments for using a government rate include the contention that the government is an entity with an almost infinite ability to spread costs over time and across large numbers of taxpayers and wide ranges of activities. This diversification ability is so wide that the uncertainty of any particular cash flow is insignificant and therefore there need be no extra charge.
Essentially, everything will average out without creating problems.

A counter to this argument is that taxpayers, like shareholders, are the holders of residual risk. Taxpayers may indeed be comfortable ignoring unsystematic risk, but should wish to be paid for systematic risk, such as the business cycle risk inherent in Small Business Administration (SBA) loans. Arguments that taxpayers should not care about lending risk would therefore hold up only if they would work equally well if we were talking about shareholders in an analogous situation.

Another argument in favor of using government borrowing rates hinges on the contention that there is a difference between a budget and an economic analysis. This has two variations. First, if we view budgeting as more of an accounting exercise, then it is the borrowing rates of the government that matter, not the theoretical costs. The further argument is that these borrowing rates are not much affected by the volatility of cash flows. Second, some argue that it is more important to avoid budgeting gamesmanship by using a rate we can all look up than it is to get the precisely right economic rate.

There are big implications for public policy, and for politics, that depend on the outcome of this debate. Use of risk-adjusted rates would tend to lower the amount of federal credit activity because any risk-adjusted rate would be higher than the government's cost of borrowing. Every credit program would, by definition, have a higher budget cost or a lower benefit. This point was certainly not lost on the politicians who ultimately decided what to put into the Federal Credit Reform Act, and I am morally certain that it was a major underlying reason for the choice of the government's borrowing rate as the discount rate.

The other effect of changing to a risk-adjusted discount rate could well be to decrease the political attractiveness of lending to higher-risk borrowers, unless interest rates on the loans themselves were also increased. I should note that riskier borrowers already have a higher budget cost because the best estimate of their credit defaults is above that for other borrowers. However, use of an increased discount rate would add to this difference. 


\section{Cost-Benefit Analyses}

Intertwined with questions concerning optimal budget rules is a need for good measures of lending effectiveness. These will probably vary with the underlying policy issue addressed by the lending program, but perhaps we can find a few common metrics. I am sure there are whole textbooks on cost-benefit analysis that could be consulted, but one of the keys to dealing effectively with policymakers is to find measurements that are simple and intuitively appealing. (Again, I'm not sure this is that different in the private sector. I did much better with CEO's and top officials of insurers and banks when I could show them the likely effect of an action on a simple metric, like return on assets, than when I tried to get much fancier.)

I have been wrestling with appropriate metrics relating to the SBA. Currently, there is a disconnect between what policymakers give as the reasons for the existence of the SBA and the measures that politicians use in practice. Many who defend the SBA on policy grounds point to perceived market failures that channel too little money to minorities and to high-risk ventures that could have major positive externalities-the next Google, for example. In essence, they see private sector lending as having a tendency to play it too safe, whether that is an actual difference of risk or one produced by discriminatory perceptions.

Unfortunately, politicians seem to impose a combination of two metrics that produces the same result within the SBA. They want as high a lending volume as possible at as low a budget cost as possible. Ideally, each of their constituents would borrow $\$ 10,000$, but the budget cost would be zero. There is a way to maximize this combined objective: lend large volumes, but only to businesses that clearly have the resources to pay the SBA back. Unfortunately, minority businesses and high-risk ventures are not likely to fall into these categories. Some minority businesses would qualify as low risk, but discrimination in our society produces risks that disproportionately handicap these businesses. After all, the very reason that policymakers want the SBA to focus on minorities is because they have more trouble getting financing from conventional sources. Lack of access to private market funds is itself a risk factor because a future cash need could arise that the SBA could not or would not be willing to fill.

What we need is a way to measure either the net gain to society from allocating resources to deserving borrowers who were not getting them, or at least a way to measure the benefit to the borrowers in terms of greater access or lower cost. We may not really need an SBA if all it is going to do is to lend at a few basis points less than borrowers would have paid for money they could have obtained without the SBA.

It may be that the only answer is a fullfledged cost-benefit analysis of some kind, but it would be very helpful if there were a simple way of approximating the same result. Simple measures, even if crude, can be preferable in some circumstances.

I have focused here on the SBA, but the same types of questions can be raised for any lending program where there is a measure of choice in who receives a loan or where there is a question as to whether to add a category of borrowers. It is a less pressing issue with student loans or other programs that take all comers who meet a fairly wide set of criteria.

\section{Simplifying Models and Data Requirements}

This leads me naturally to another general question. Is there a way to simplify some of the more advanced techniques so that data estimation and input problems do not overwhelm the theoretical advantages? There is always a practical tension in modeling between the desire to incorporate greater realism through additional variables, and a finer division of categories and time periods, versus the need to strive for an elegant simplicity. For the first years after passage of the Federal Credit Reform Act, the big modeling issues seemed to involve persuading agencies to make the commitment to model in sufficient detail and to capture the data necessary for the basic analysis.

I have started to sense that some government departments have now overshot in the other direction, adding more variables because they can rather than because they make a significant differ- 
ence. This strikes me as a particular temptation in a bureaucracy, private or public, for at least two reasons. First, it is safer to be able to say that a variable has been taken into account than it is to argue that it is not important. Second, there is an advantage sometimes in having a model so complicated that no one can dispute your conclusions. Clarity may not always be seen as a virtue.

This temptation probably cannot be eliminated, but it may be that economists can help us focus on some key variables that ought to be considered or statistical techniques that would help us capture the essence of a financial institution.

\section{Budgeting for Insurance Programs}

Perhaps I have already been in Washington too long, but I would now like to expand my empire beyond my stated mandate of federal credit programs by talking a little about federal insurance activities. The big theoretical question is, How can we improve federal budgeting for insurance programs? There was a plan to follow up the Federal Credit Reform Act of 1990 by expanding the concepts to include insurance. This fell through, and we have continued to use the current inadequate system of cash budgeting.

Cash budgeting for insurance activities is a disaster, in my opinion. Let me give you two examples.

PBGC. Exhibit A is the PBGC. At last count, it was $\$ 23$ billion in the hole and digging deeper every day, according to generally accepted accounting principles (GAAP), which appear to reflect the PBGC's economics quite well. However, the cumulative effect of the PBGC on the federal budget, since it came on-budget in the early 1980s, is a $\$ 12$ billion contribution to deficit reduction. There is a $\$ 35$ billion difference between these two numbers, and they have opposite signs.

Here's how it happened. The federal budget essentially treats the PBGC as if it were two entities. There is an on-budget revolving fund that takes in all premiums and earns investment income on those premiums. There is an off-budget quasi-trust fund that represents all of the assets taken over from failed pension funds and the investment earnings on those assets. Pension payouts come partially from the revolving fund and partially from the quasi-trust. The proportion is based on the original funding ratio of the pension plan for which the check is being paid. If a company's plan was 60 percent covered by its assets when the PBGC took over, then 60 percent of the pension checks paid out for their retirees come from the quasi-trust and the rest from the revolving fund. Other expenses are split on a formula basis that is managed so that almost all expenses are covered from the off-budget quasitrust and do not contribute to the federal deficit.

Pension payments are very long-term obligations, so the PBGC is collecting large premiums now to build up a reserve to eventually pay all of the pensions for the claims it has taken on. This means that for many years the cash inflows from these premiums have more than offset the early years of pension payments.

The PBGC's excellent GAAP reporting has helped to highlight its problems and is one of the reasons why Congress is close to acting to reduce the ultimate problem by increasing premiums and forcing higher levels of pension funding. However, I firmly believe that, if the PBGC's effect on the federal budget had shown the same pattern of increasing GAAP deficits, there would have been action earlier. It was around April Fool's Day only last year that Congress actually loosened funding requirements by raising the discount rate used for funding calculations and allowing airlines and steel companies to put in only 20 percent of their annual minimum required contributions. If this had been seen to raise the short-term risk of a significant hit to the budget, there might have been a more serious examination of the desirability of the funding changes. Perhaps it was the right public policy outcome or perhaps politics would have forced it through even if it were not, but at least the issues would have been addressed.

Flood Insurance. Flood insurance is another example of the perils of cash accounting for insurance. The National Flood Insurance Program (NFIP) is the only flood insurance provider for most homes in flood-prone areas. Premiums are deliberately subsidized for older structures, so that about a quarter of all flood insurance policies are charged a rate roughly 40 percent of the best 
actuarial estimates. My calculations from the insurer's actuarial review suggest that the subsidy amounted to $\$ 1.3$ billion last year. The other three-quarters of the structures, mostly newer, are charged actuarially derived rates that are intended to cover the expected cost of all future flood events, including the most catastrophic. For comparison, total premiums for the program amounted to $\$ 2$ billion last year, so the subsidy rate for the entire program would be over onethird on an economic basis, despite the fact that many subprograms bear no subsidy at all.

It happens that, until this year, the flood insurance program was lucky enough not to have suffered the kind of massive flooding that resulted from Hurricane Katrina or even something a notch or two smaller but still huge. Thus, the NFIP could proclaim that it charged sufficient premiums to pay for a "historical average loss year," even though it also stated that there were substantial subsidies to one group and that the other group paid actuarially fair rates (which implies no overpayment to make up for the subsidies on the other group). It also proudly reported that since the early 1980s it had never been a drain on the taxpayer, except for three borrowings that it had paid back with interest.

There is something wrong when a government agency can be explicitly subsidizing premiums by $\$ 1.3$ billion while presenting itself as being breakeven and no drain on the taxpayer. Obviously, the circle is squared by the fact that insurers against catastrophic losses who charge actuarially fair premiums make money 9 years out of 10 and lose most of it back in the 10th year. In the NFIP's case, it was more like 34 years out of 35 , but this current, 35 th year is a doozy. Hurricane Katrina will cost the program $\$ 23$ billion, compared with a figure of $\$ 14$ billion for all previous claims since inception in 1969, not adjusted for inflation. This far exceeds the program's capacity to pay and will certainly come principally from taxpayers.

\section{"Credit Reform" for Insurance}

There seems to be a fairly strong consensus among budget policy analysts that there does need to be an equivalent to the Federal Credit Reform Act for federal insurance activities. However, there is also concern for how to design such a system so that it precludes an excessive level of gamesmanship. I have spoken with prominent budget experts who would be very scared to let agencies start using probability analysis with relatively unpredictable insurance risks. What should one do about terrorism risk insurance, for example? Private insurers argue strongly that the risk is uninsurable in the first place partly because it is too difficult to ascribe probabilities to potential attacks. Do we want government agencies trying this at home?

My own view is consistent with a comment from Lord Keynes, which I will paraphrase, "a bad measurement on sound principles is better than no measurement at all." We effectively use measurements at or close to zero for these events now. It seems sounder and more conservative to use a positive, probabilistic estimate.

If we had adopted this approach earlier, the debate about the last loosening of pension funding rules would have required a discussion of the probable loss to the PBGC. Congress could always have fudged the analysis, but I would much rather have a standard set of rules that made some sense and force them to be explicitly overridden if politics intervenes. I want inertia to be our friend, not our enemy, because there is certainly enough of it around, and not just in the public sector.

The flood insurance numbers would even more certainly have been accurate. The data is already there, as I noted, in the actuarial review and much of it is based on technical, engineering estimates. Good budgeting would have highlighted the figure rather than obscured it.

To repeat, a budget reform act for federal insurance programs would be very helpful. The economics profession could do a real public service by helping to shape the principles under which such an act would operate and to raise the visibility of the issue so that policymakers will view it as a priority.

It may be worth underlining the obvious, which is that there will be political opposition. Right now the budget costs appear lower than the economic costs would be. Every decade or so the costs shoot up as a catastrophe hits, but that, as we are seeing once again, is the easiest time to 
get funding. It is politically easiest to have low costs for the large majority of years and shockingly high costs in the occasional year that you can blame on Mother Nature.

\section{PEOPLE AND TOOLS}

I started this talk with a focus on overall structural issues for federal financial institutions and then segued to budgeting issues. Structure and budget together carry a very heavy weight of responsibility for the success of any public institution, especially in the absence of a private financial market to provide another kind of discipline. However, there is more to running a financial institution than this. It takes people and it takes tools to make the institutions run.

\section{Human Resources}

Unfortunately, there are some human resources issues that are important but difficult to resolve. The most basic is that government service is considerably less lucrative than working for a private sector financial institution. Many arms of government face this difficulty, but it is particularly acute for the federal financial institutions, simply because similar skills fetch so much more in the private sector.

This problem is not unique to the public sector. The rating agencies, for example, need employees with excellent finance skills, but are not in a position to pay as much as investment banks or the more sophisticated commercial banks. The solution they have developed is to find ways to retain a relatively small senior staff, who can maintain the culture and quality standards, while organizing the rest of the work so that it can be performed by younger analysts who will remain for a few years at a time. The rating agencies end up serving as one of the training grounds for budding bankers and equities analysts.

Government financial institutions can often obtain quite talented staff for positions with real prestige and authority, but only with the implicit understanding that the new hire will probably only stay for two years and then move to the private sector to exploit their government experience and new connections. This biennial pattern is so common that it is sometimes referred to as a "Mormon Mission," since most adult males in that church go off for two-year missionary stints once in their life.

This turnover is an issue, but the more difficult problem is probably at the levels starting just below these more prestigious positions. There is a real need for financial sophistication, but it is not structurally easy to provide the requisite training and it is even harder to retain employees once they have those valuable skills.

We could use the advice of labor economists on this one. I have wondered if it would be beneficial to have a Certificate in Government Financial Institutions Management that would require a specific set of training, but would entitle employees to higher pay. Congress is very leery of increasing pay, but is more likely to be convinced by a payfor-skills trade-off than by a simple increase for financial institutions employees. Government doctors and certain employees of bank regulatory agencies have higher compensation limits, so there is some scope for adjustment.

\section{Management Tools}

There is also a problem that most federal financial institutions have too low a ratio of capital to labor. This is a serious deficiency because there has been a whole revolution in the financial services industry in the private sector in the last couple of decades. Much more information is now collected on each borrower, and loan and statistical techniques have been honed to understand how to market, price, and manage loans. Management systems have evolved to ensure every advantage is wrung from this greater understanding.

Unfortunately, Congress persists in viewing administrative expenses as a bad thing, rather than considering what the best trade-off might be between expenses and total profit or loss. Switching to the insurance side for a moment, many of the private property-casualty insurers that I have admired most have focused on intensive, and expensive, underwriting and management. They have accepted higher expense ratios, recognizing that the more important ratio was 
the loss ratio, which can be reduced by careful client selection and pricing.

Once again, by the way, there is a budget process issue that exacerbates the basic problem. The net-present-value calculations that I described earlier for calculating the budget effects of federal lending activity explicitly do not include administrative expenses. Congress wished to maintain its control of the annual appropriations process for expenses rather than having future expenses be projected as part of the net-present-value calculations. As a result, investments in systems that should reduce future expenses still show up as a hit to the budget deficit now, without any immediate benefit from the expected future savings.

The unwillingness to invest in systems may be a chicken and egg type problem, since I understand that many of the computer systems that were supposed to bring government departments into modernity have instead cost large sums of money to little purpose. Nonetheless, I believe that appropriate software and management tools must be brought into the federal financial institutions, even if the transition is at times a painful one.
- Too much of the advice policymakers receive comes from vested interests and too little from objective sources.

- Developing clear answers to a series of analytical questions would provide firmer guidance to those policymakers and reduce policy errors.

- We all need to help. Theorists can focus on answering those questions that are genuinely open and on explaining the answers to those that are known. Practitioners can redouble their efforts to apply sound principles to specific issues. Both groups need to talk more to the other.

- Finally, I highly recommend www.coffi.org. We welcome your suggestions as to how we can be more helpful to policymakers, journalists, and the interested public.

Thank you very much.

\section{CONCLUSIONS}

My summation will be brief.

- Federal financial institutions are extremely important.

- Not enough attention is paid to them. 
